\title{
Article
}

\section{Optimal settings for childbirth}

Setola, Nicoletta, Iannuzzi, Laura, Santini, Marco, Cocina, Grazia, Naldi, Eletta, Branchini, Lucia, Morano, Sandra, Escuriet Peiro, Ramon and Downe, Soo

Available at https://clok.uclan.ac.uk/24584/

Setola, Nicoletta, Iannuzzi, Laura, Santini, Marco, Cocina, Grazia, Naldi, Eletta, Branchini, Lucia, Morano, Sandra, Escuriet Peiro, Ramon and Downe, Soo orcid iconORCID: 0000-0003-2848-2550 (2018) Optimal settings for childbirth.

Minerva Ginecologica . ISSN 0026-4784

It is advisable to refer to the publisher's version if you intend to cite from the work.

10.23736/50026-4784.18.04327-7

For more information about UCLan's research in this area go to http://www.uclan.ac.uk/researchgroups/ and search for <name of research Group>.

For information about Research generally at UCLan please go to http://www.uclan.ac.uk/research/

All outputs in CLoK are protected by Intellectual Property Rights law, including Copyright law. Copyright, IPR and Moral Rights for the works on this site are retained by the individual authors and/or other copyright owners. Terms and conditions for use of this material are defined in the policies page.

\section{CLoK}

Central Lancashire online Knowledge www.clok.uclan.ac.uk

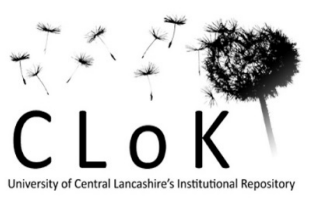




\title{
Optimal settings for childbirth
}

\author{
Nicoletta SETOLA 1 *, Laura IANNUZZI 2, Marco SANTINI 3 , \\ Grazia G. COCINA 4, Eletta NALDI 5, Lucia BRANCHINI 6, \\ Sandra MORANO ${ }^{7}$, Ramon ESCURIET PEIRÓ ${ }^{8}$, Soo DOWNE 9
}

1TESIS Centre, Department of Architecture, University of Florence, Florence, Italy; ${ }^{2}$ Physiological Pregnancy Pathway and Margherita Birth Centre, Department of Health Care Professions, Careggi University Hospital, Florence, Italy; ${ }^{3}$ Department of Health Science, University of Florence, Florence, Italy; ${ }^{4}$ Department of Architecture and Design, Polytechnic University of Turin, Turin, Italy; 5 Department of Architecture, University of Florence, Florence, Italy; ${ }^{6}$ MondoDonna Onlus, Association for support and Integration of Immigrant Populations and Vulnerable Women, Bologna, Italy; ${ }^{7}$ Department of Neuroscience, Rehabilitation, Ophthalmology, Genetics and Maternal-Infant Sciences (DINOGMI), University of Genoa, Genoa, Italy; ${ }^{8}$ Catalan Health Service, Generalitat de Catalunya, Barcelona, Spain; ${ }^{9}$ Research in Childbirth and Health Unit (ReaCH), School of Community Health and Midwifery, University of Central Lancashire, Preston, UK

*Corresponding author: Nicoletta Setola, TESIS Centre, Department of Architecture, University of Florence, Via San Niccolò 93 , 50125, Florence, Italy. E-mail: nicoletta.setola@unifi.it

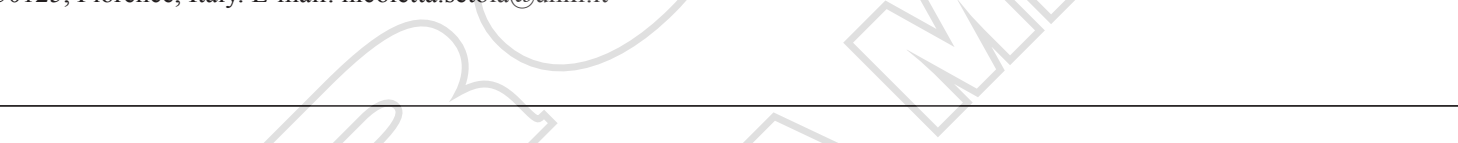

\section{A B S TR A C T}

Many studies highlight how health is influenced by the settings in which people live, work, and receive health care. In particular, the setting in which childbirth takes place is highly influential. The physiological processes of women's labor and birth are enhanced in optimal ("salutogenic," or health promoting) environments. Settings can also make a difference in the way maternity staff practice. This paper focuses on how positive examples of Italian birth places incorporate principles of healthy settings. The "Margherita" Birth Centre in Florence and the Maternity Home "Il Nido" in Bologna were purposively selected as cases where the physical-environmental setting seemed to reflect an embedded model of care that promotes health in the context of childbirth. Narrative accounts of the project design were collected from lead professional and direct inspections performed to elicit the key salutogenic components of the physical layout. Comparisons between cases with a standard hospital labor ward layout were performed. Cross-case similarities emerged. The physical characteristics mostly related to optimal settings were a result of collaborative design decisions with stakeholders and users, and the resulting local intention to maximize safe physiological birth, psychosocial wellbeing, facilitate movement and relaxation, prioritize space for privacy, intimacy, and favor human contact and relationships. The key elements identified in this paper have the potential to inform further investigations for the design or renovation of all birth places (including hospitals) in order to optimize the salutogenic component of any setting in any country.

(Cite this article as: Setola N, Iannuzzi L, Santini M, Cocina GG, Naldi E, Branchini L, et al. Optimal settings for childbirth. Minerva Ginecol 2018;70:000-000. DOI: 10.23736/S0026-4784.18.04327-7)

KEY WORDS: Birthing centers - Health facility environment - Sense of coherence - Midwifery.

$\mathrm{I}$ $t$ is widely recognized that health is influenced by settings at different levels, from the public spaces in the city to the room where we work and live. Buildings themselves are a means to support health. This concept is the basis of specific research area of interest identified as healthy buildings or health promoting building, which then led to the development of the concepts of healthy school, healthy workplaces, healthy hospitals. ${ }^{1}$

The beginning of the $20^{\text {th }}$ century was characterized by the awareness of the multiple nega- 
tive consequences for health related to the poor conditions of many living spaces. The need to enhance the possibility for people to enjoy natural light, clean air, sun and adequate ventilation in the living space represented a key driver for the building design of healthier residential areas. Gehl et al. ${ }^{2}$ talk about the "physiological and functional aspects" of space, indicating the physiological wellbeing of the users to be a main theme of interest. Furthermore, the concept of health stated by the World Health Organization $(\mathrm{WHO})^{3}$ marked the need for including social and mental wellbeing as part of the concept of individuals' health.

The interconnection between physical, emotional and social wellbeing is apparent in the context of health care spaces (e.g. hospital, clinics, community centers). Several architectural approaches like biophilia, ${ }^{4}$ superarchitecture, ${ }^{5}$ salutogenic design, ${ }^{6}$ healing architecture ${ }^{7}$ stress how the design of a building can support the physical and mental health of users influencing also the healing process. However, a health setting environment is also modifiable by the professionals that work in it. In this sense, staff can influence the wellbeing of the users both directly and indirectly within a setting.

In the light of these considerations, the term "setting" should be used in its broader sense, that includes both the physical and the organizational-relational aspects of a space. WHO defines the setting for health as "the place or social context in which people engage in daily activities in which environmental, organizational, and personal factors interact to affect health and wellbeing"8. This suggests that an analysis of, and investment in, the setting of physical and organizational spaces is needed. 9

\section{Health(y) settings and childbirth}

The physical characteristics of birthplaces can be examined through a salutogenic perspective. Endorsing a salutogenic approach in the designing of health settings means to design in the light of the users' social and psychosocial needs, considering their experiences, ${ }^{10}$ but also knowing and acknowledging the human body system, the physiology and the senses, as well as the pos- sible long-term health conditions. ${ }^{11}$ The key concepts in Antonovsky's salutogenesis theory (manageability, comprehensibility and meaningfulness) have been acknowledged to be relevant also in building terms.6, 10,11 Examples of practical translations of these concepts include the creation of spatial layout and internal features (i.e. use of colors, art, natural materials and connections with nature) that can allow an intuitive wayfinding, promote a sense of belonging to a place, enhance the functionality of a space, staff sense of control, and users' experience of feeling safe. $6,10,11$

Good quality systematic reviews show that labor and birth tend to need less interventions if women feel safe, if they have room to move around, if they can access pools or baths for pain relief, if there is space for birth companions, and if their care-giver is enabled to be with them, rather than being distracted by the need for constant observation of monitoring machines, and the need for frequent data recording. ${ }^{12-16}$

However, the design of most standard labor wards worldwide prioritizes professionals-centered emergency and high-tech related activities with less attention to the creation of a user-centered environment in which the above evidencebased practices can take place. The rationale used for designing hospital labor ward (HLW) is based on criteria included on tools supporting design but also on approaches that became routine practice for a matter of habit or convenience.

Existing guidelines for hospital labor ward design ${ }^{17-20}$ provide indications on the necessary typology and size of the spaces aimed to support the activities of a labor-ward. However, the activities acknowledged, and the subsequent recommendations, mostly related to strictly technical-clinical practices or to safety issues, with no or little consideration of the plethora of all other features impacting on the above-mentioned concept of health. A clear example is offered by the general approach to the design of a labor room in HLW that is centered around the hospital bed (that dominates the space), the medical interventions and related necessary equipment that can be performed around it and the pathways to use in case of emergency. Recommendations concerning the design and building of physical fea- 


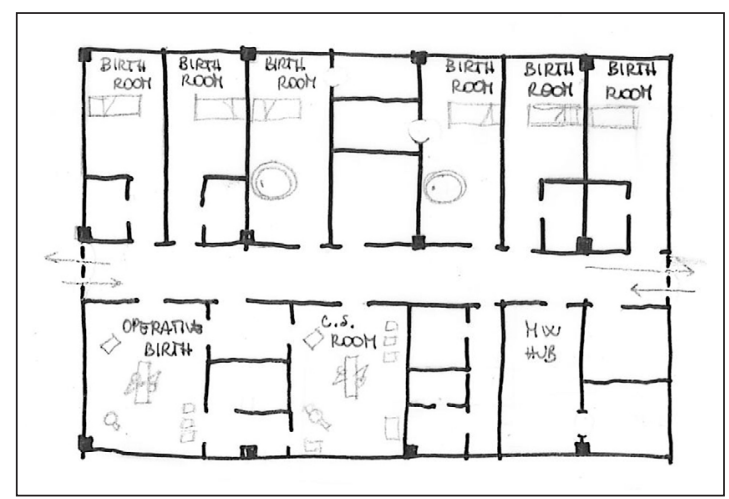

Figure 1.-Plan of standard Hospital Labour Ward.

tures in the room that can promote and support physiology appear to be almost absent.

The usual location of HLW discloses elements of building design that might be also based on habit. HLWs are mostly located in rectangular buildings which have a bearing structure in pillars, sector-based spaces, and long corridors with rooms on sides and with no or little access to light in the middle. This layout is based on a functional logic that aims to optimize surfaces, systems connections, transfer movements and costs, leading to the creation of highly repetitive and squared spaces. This standard design of current hospital labor wards has started to emerge as suboptimal in terms of staff wellbeing ${ }^{21}$ (Figure $1)$.

New approaches to standard birth environments have, hence, started to be developed in this area. ${ }^{22-24}$ This paper describes and builds on this existing work.

\section{Moving and changing birth settings}

Europe has seen a change for what concerns place of births especially from the " $60 \mathrm{~s}$ when there was largescale movement of birth from homes to hospitals. While this had positive effects on the women and babies who really needed hospitalbased care, this move led also to a progressive increase in the medicalization of childbirth and associated iatrogenic damage. These include, short-term and long-term health effects related to the overuse of intrapartum interventions and in particular to the epidemic use of caesarean section at global level, ${ }^{25}$ the embedding of indus- trial models of care connected to large and busy hospital units where women and families are approached as in an assembly-line process, and the loss of the concept of birth as a life-social event and not only as a 'health process' in maternity systems. ${ }^{26}$

The need for change, first and foremost in the mother and babies' interests, led to the paradigm of "humanization of birth" 27,28 and all the related initiatives. Particularly since the ' 80 s, the characteristics of hospital spaces began to be perceived as connected to the (over) medicalization of birth, with evidence starting to show how birth settings could impact on women's bodies, feelings, choices, and consequently birth outcomes. ${ }^{29}$ Alongside debates on homebirths, women's choices and rights, the push for humanizing birth has driven the design of different birth spaces as factor for transforming care, especially within institutional settings, as they still represent the main birth environment in most countries.

In the Italian context, the implementation of "Homelike maternity centres" 30 started in 1984 with the creation of "the natural birth room" in the small remote hospital of Poggibonsi in Tuscany. This room offered for the first time in a hospital an intimate, comfortable and colorful environment with a double bed, pillows and a small pool. In this room the woman could give birth and then stay together with the newborn and family. This model was groundbreaking for the time. ${ }^{31}$

Another turning point for birthplaces in institutional settings occurred in 1999, with the opening of first Italian alongside birth Centre, the Alternative Birth Centre (ABC) of Genoa. The $\mathrm{ABC}$ was born from a two-step project: the first one consisting in a review of the current barriers to the support of physiology of childbirth; the second including visit to several Maternity and Midwife-led Units abroad. The ABC was a model and a trigger for other similar experiences, together with the later established birth center in Florence, the Margherita Birth Centre and the last public alongside unit of Sant'Anna Hospital in Turin. According to the Ministry of Health ${ }^{32}$ these represent the only three midwife-led unit in the Italian context. 
There are also other out-of-hospital birth settings, defined by their coordinating body ${ }^{33}$ as "maternity homes." Unlike birth centers, these are private structures, developed as houses and social spaces rather than clinical settings and generally run by a group of independent midwives or associations of midwives and women in collaboration with other professionals and stakeholders. To date there seem to be 11 maternity homes scattered on the Italian territory, mostly in northern and central geographical areas. ${ }^{34}$ Only a few regions recognize them by law also as birth places. These maternity homes are mostly identified as social spaces where the birth event is seen as one (but a crucial one) part of the social/life events welcomed in those facilities.

\section{Exploring healthy birth settings}

Birth centers and maternity homes appear to be ideal places for analyzing, from a salutogenic perspective, how physical spaces can contribute to promoting and supporting health, and to enabling a birth place to be a 'healthy setting' for the users and professional who inhabit it.

The aim of this work was, thus to explore whether and how existing birth centers and maternity homes in the Italian context endorse a salutogenic approach in their architecture and what elements were perceived to particularly embody the model of care and to contribute to make of the facility a healthy setting for childbirth.

\section{Methods of the research}

Two cases were purposively selected among the Italian existing birth centers and maternity homes, being identified to be particularly interesting for the aim of the research as well as easily accessible to the research group. One was the "Margherita" (the "Daisy") Birth Centre in Florence and the other the maternity home "Il Nido" ("the Nest") in Bologna.

The main research questions of interest were:

- what process did lead to the realization of the facilities?

- how important was the collaboration between different stakeholders?
- what spatial aspects were planned and adopted to promote users' and professionals' health?

- how much does the architectural environment reflect the model of care proposed

- in the light of the current experience, what strategies can be adopted in order that these two aspects are coherent with each other?

In order to answer to these questions, narrative accounts concerning the ideas underpinning the project design and feedback in the selected birthplaces were collected by NS, LB and LI from lead professionals (2 lead midwives and 1 lead consultant obstetrician) between June and July 2018.

Direct inspections of the service were then performed by members of the research team (NS, $\mathrm{GC}, \mathrm{EN}, \mathrm{LI}, \mathrm{LB}$ ) in order to deepen the insights emerging through the professionals' narratives.

The resulting case reports focused on the premises and the development of the project and the description of the elements of the layout identified as significant in promoting health and reflecting the model of care. Table I was created to contrast features of the selected settings in comparison also with standard HLW design in order to illuminate components that could optimize the health of childbearing women, their birth companions, and attending staff in any birth setting. ${ }^{17-20}$

\section{Results}

\section{Case 1: The Margherita Birth Centre}

The project underpinning the Margherita Birth Centre represented an extraordinary process for its time in the development of birth setting within hospitals in the Italian context (see Supplementary Digital Material 1, Supplementary Text File 1).

The building was inaugurated in 2006 but the Margherita Birth Centre started its activity later in 2007. Coherently with the project, the Margherita is constituted by a two-floor round building located inside the area of the Careggi University Hospital, separated yet connected through a corridor to the Maternity Department. The birth center hence can be fully described as an alongside midwife-led unit 35,36 (Figure 2). 
TABLE I.-The key features set out for the birth centre, the maternity home and a standard labour ward. The statements regarding the Margherita were taken from personal notes and documentation of MS and field notes from NS and LI. The statements about Il Nido are based on pictures and field notes taken by LB and LI. The features of the standard HLW are taken from technical guidelines ${ }^{17-20}$ and professional experience of NS, EN and GC.

\begin{tabular}{|c|c|c|c|}
\hline & Margherita BC & Il Nido MH & Standard HLW \\
\hline $\begin{array}{l}\text { Impetus for } \\
\text { creating the } \\
\text { space }\end{array}$ & $\begin{array}{l}\text { Give new substance to the concept of physiology } \\
\text { of birth within the institution, make changes } \\
\text { in the organization of current care in hospitals, } \\
\text { and give shape to this change. Design an ideal } \\
\text { 'container' for this, being as innovative and } \\
\text { simple as possible in its essential elements and } \\
\text { process } \\
\text { Need for collaborative work between } \\
\text { obstetricians, midwives, neonatologists, } \\
\text { psychologists, sociologists and architects (that } \\
\text { in many cases were also mothers and fathers) } \\
\text { To give women and families intimate spaces, that } \\
\text { are private and respectful of the birth process } \\
\text { (Reduce) overuse of unnecessary medical } \\
\text { interventions }\end{array}$ & $\begin{array}{l}\text { Need to give women an out of } \\
\text { hospital place of birth that } \\
\text { could meet the needs of those } \\
\text { families who otherwise could } \\
\text { not give birth at home as too } \\
\text { far from the hospital } \\
\text { Implement a place that } \\
\text { promoted continuity of care } \\
\text { for women and their families } \\
\text { in a place that could be useful } \\
\text { for educational purposes } \\
\text { and that could promote a } \\
\text { certain philosophy of care } \\
\text { and parenthood in which } \\
\text { midwives could be identified } \\
\text { as professionals }\end{array}$ & $\begin{array}{l}\text { Guarantee safety to } \\
\text { women and baby, } \\
\text { ensure staff efficiency, } \\
\text { sustainable costs }\end{array}$ \\
\hline $\begin{array}{l}\text { Philosophy } \\
\text { underpinned } \\
\text { design }\end{array}$ & $\begin{array}{l}\text { Safety, functionality, wellbeing for women, } \\
\text { midwives and maternity care assistants, beauty } \\
\text { Most of the traditional elements of hospital } \\
\text { engineering were subverted, as the physical } \\
\text { layout did not come from a purely logical, } \\
\text { detached ideational process but from drawing } \\
\text { something appropriate to a living, tangible, } \\
\text { reality } \\
\text { Physical environment for the birth and the } \\
\text { relationship of that environment with medical } \\
\text { and psychological aspects of pregnancy and } \\
\text { childbirth focusing on three main objectives: } \\
\text { to put the users of the service at ease; to enable } \\
\text { the people working in the birth centre to feel } \\
\text { good; and to recover the aesthetic value in the } \\
\text { context of hospital buildings }\end{array}$ & $\begin{array}{l}\text { To understand both the need of } \\
\text { families and midwives } \\
\text { Build on the opportunity for } \\
\text { redesign of the existing } \\
\text { building } \\
\text { Possibility of staying in a } \\
\text { relaxed and restorative } \\
\text { atmosphere, in a peaceful } \\
\text { outdoor space in connection } \\
\text { with nature } \\
\text { Feeling at home }\end{array}$ & $\begin{array}{l}\text { Elements of hospital } \\
\text { engineering: } \\
\text { modularity, } \\
\text { standardization, layout } \\
\text { efficiency, safety } \\
\text { 'Humanization' of } \\
\text { hospital spaces }\end{array}$ \\
\hline $\begin{array}{l}\text { Layout } \\
\text { configu }\end{array}$ & $\begin{array}{l}\text { Independent building linked to the hospital by } \\
\text { a corridor at the level of the first floor where } \\
\text { LDR and CS theatre are present } \\
\text { New building, } 2 \text { floors } \\
\text { The layout abandons linear schemes to focus on } \\
\text { a central space around which various functions } \\
\text { run, distributed to cloister } \\
\text { Circular shape, rounded lines } \\
\text { The birthing area is a protected space both } \\
\text { emotionally and physically }\end{array}$ & $\begin{array}{l}\text { Stand-alone villa } 10 \text { minutes by } \\
\text { car from the Hospital } \\
\text { Existing building, } 2 \text { floors } \\
\text { The birthing area is a protected } \\
\text { space both emotionally and } \\
\text { physically } \\
\text { Rectangular shape building }\end{array}$ & $\begin{array}{l}\text { Area inside the } \\
\text { perimeter of the } \\
\text { hospital building } \\
\text { Rectangular shape with } \\
\text { corridor in the middle } \\
\text { and rooms in linear } \\
\text { sequence }\end{array}$ \\
\hline $\begin{array}{l}\text { Location of the } \\
\text { staff area }\end{array}$ & $\begin{array}{l}\text { in the middle of the birth rooms, in a compact } \\
\text { space similar to a 'cloister' with many } \\
\text { advantages from both a practical and a } \\
\text { psychological point of view. "It offers a centre } \\
\text { of reference for women and at the same time } \\
\text { for midwives and maternity care assistants; } \\
\text { the environment encourages relationships } \\
\text { between users and midwives creating a sense } \\
\text { of identification and intimacy within a setting, } \\
\text { like the public hospital one, to which, for a } \\
\text { long time yet, women will refer for being cared } \\
\text { during childbirth" (by Bianca Lepori in the } \\
\text { Project report) }\end{array}$ & $\begin{array}{l}\text { Near the birth rooms } \\
\text { The space gives the possibility } \\
\text { to midwives to rest and chill in } \\
\text { a more separated and intimate } \\
\text { space }\end{array}$ & $\begin{array}{l}\text { Along the corridor, in } \\
\text { sequence with the } \\
\text { other rooms }\end{array}$ \\
\hline
\end{tabular}


TABLE I.-The key features set out for the birth centre, the maternity home and a standard labour ward. The statements regarding the Margherita were taken from personal notes and documentation of MS and field notes from NS and LI. The statements about Il Nido are based on pictures and field notes taken by LB and LI. The features of the standard HLW are taken from technical guidelines ${ }^{17-20}$ and professional experience of NS, EN and GC (continues).

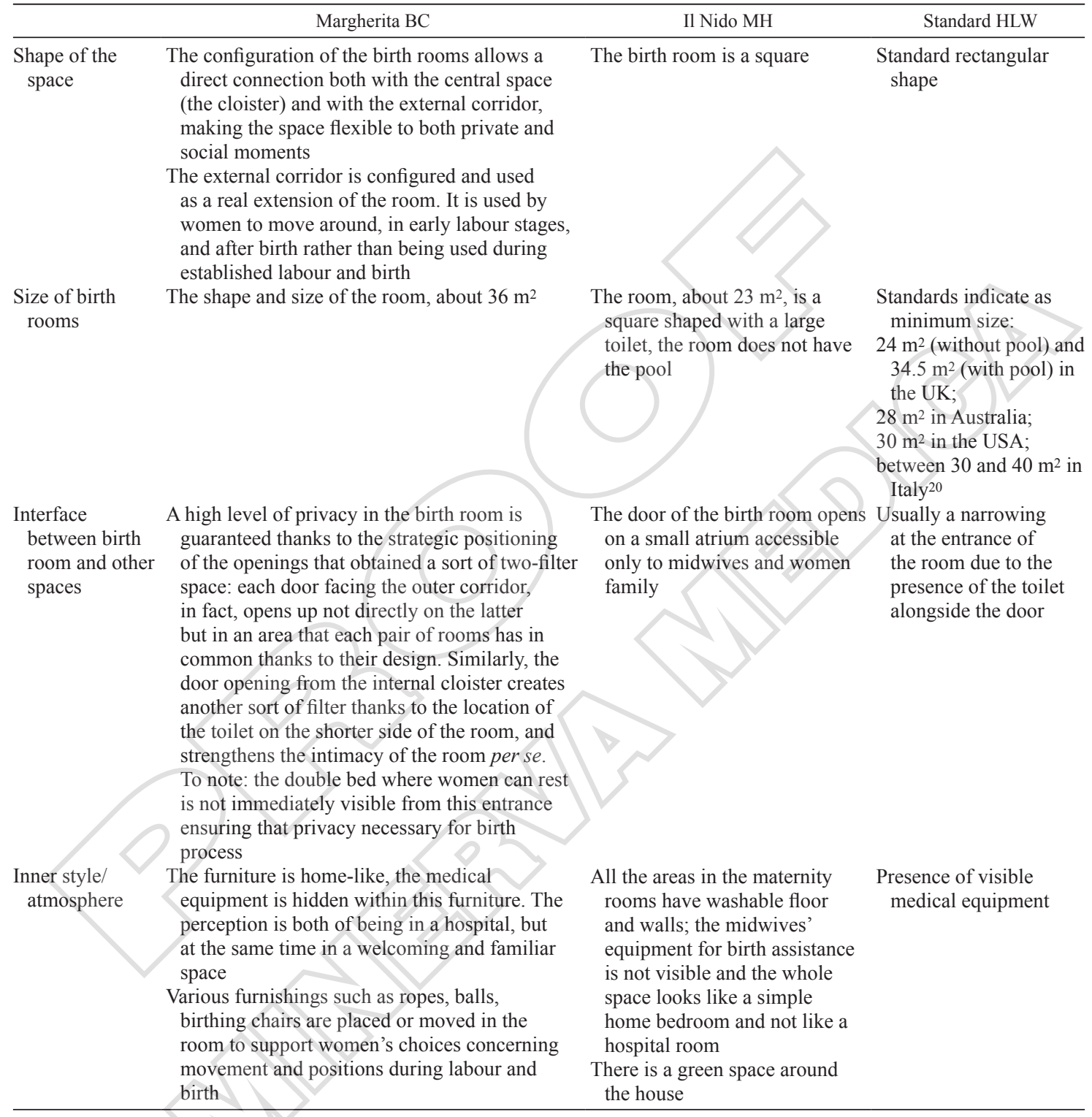

Both the floors of the building expand from core 'cloisters' in a circular system: at the ground floor this is represented by a pool used for antenatal and postnatal classes activities. All around the cloister represented by the pool at the ground floor, are located the other rooms and areas dedicated to birth preparation and antenatal care besides public spaces accessible to the community.
This includes a conference room that is used both to run training courses for professionals and information/cultural meetings with the local population.

The physical setting of the Margherita has to be hence seen as a whole and not only identified with the birthing area on the first floor. The physiological pathway offered to women and fami- 


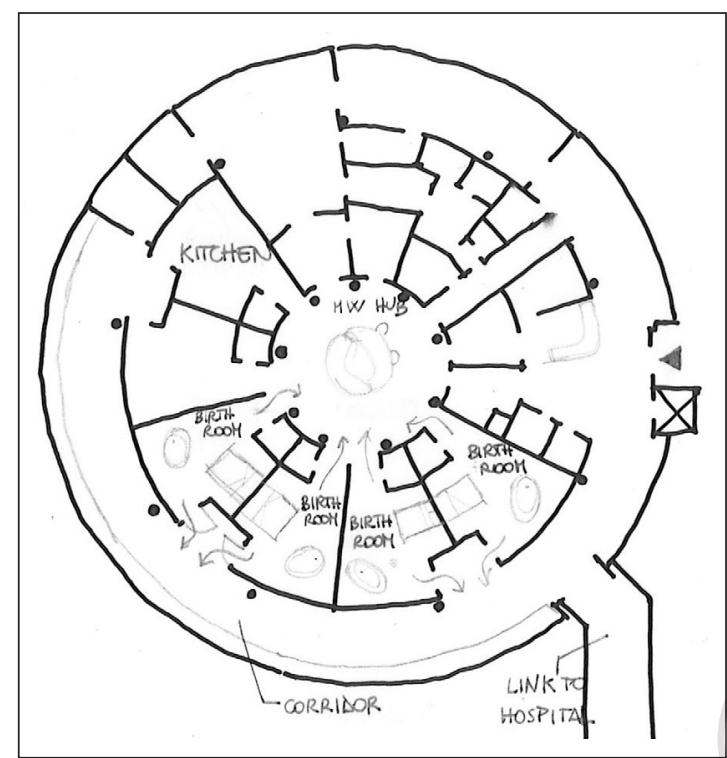

Figure 2.-Architectural plan of the Margherita Birth Centre.

lies involves more than intrapartum care. Both the architectural and clinical pathway that exist in the center frame the birth center as "not just a place where to give birth, [but] it is much more, it's a team and a program". Of this, the team is represented by: "the family... midwives, gynaecologists, neonatologists, nurses and other members of the community in which the birth centre is inserted... the birth centre program includes care during the prenatal and postnatal period as well as during birth". ${ }^{37}$

The configuration of spatial layout of the first floor shown in Figure 2 can be interpreted as a sequence of three concentric rings. The first, the innermost core, is the central fulcrum where the midwives' station is located. By locating the midwives' station in a barycentric and equidistant way from all the rooms, a strong and constant perception of the presence of midwives for women is enhanced.

The second, intermediate circle hosts the five rooms where users stay before during and after birth, the areas for outpatient clinics, counselling and triage services, a room for neonatal emergency equipped for resuscitation, and a small rest room for staff. As regards the specific layout of the five rooms they are all home-like environments, with an en-suite bathroom, equipped to host the whole family for the entire staying at the hospital. ${ }^{31}$ Four of them have a birthing pool and a double bed, while the other one does not have the pool and includes two single beds that can be used by women close to discharge to free the other rooms for laboring women in case of need. The equipment to use in case of emergency is hidden within the furniture. The rooms have no windows but skylights, on the wall connecting to the external circular area, that offer a limited access to natural lights.

Externally, a generous bright corridor that overlooks the outside landscape delineates the outer circle of the birth center. Large windows running along the perimeter allow a view on external landscape and natural lighting of the spaces (Figure 3). Together with the intermediate level, this third ring of the structure also represents a social place, where exchange of experiences between women and families, visitors, friends, midwives and maternity assistants can occur. Many professionals, as well as pregnant women and mothers of babies admitted to the nearby NICU, also use the common areas, in particular the corridor, for rest and relaxation. This illuminates the capacity of the environment for restoration, and contribution to general wellbeing also of a larger community of users.

Several midwives reported the round shape of the building to be challenging to work with at first, especially given their habituation to linear spaces. The connection and relationship between spaces and people appears to be foster by integrated design, but not automatically ensured by it. These features need to be nurtured by professionals' attitude and commitment to a relationship-centered model of care.

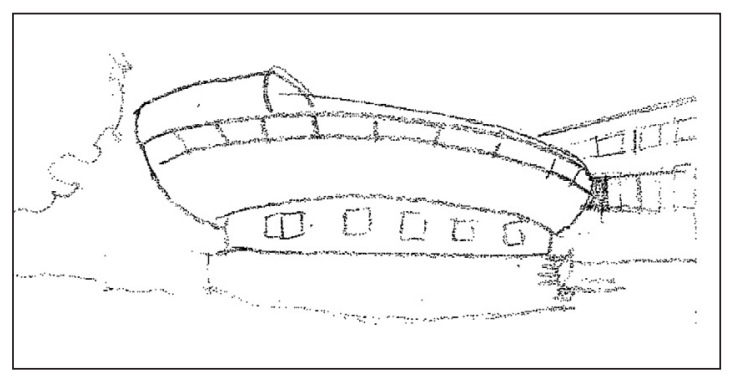

Figure 3.-External view of the Margherita Birth Centre. 


\section{Case 2: The Maternity Home Il Nido}

The Maternity Home Il Nido represents another kind of setting aimed at the promotion of dehospitalization, demedicalization of birth, and promotion of the health of women and families. It part of the private health sector, and it is managed by a small team of midwives that provides continuity of care from conception until the first year of the baby and onward. Like the Birth Centre, education and research programs also take place there.

The midwives practicing in the Il Nido have been involved in homebirth and caseloading, as independent professionals, since the 1980s. In the early 1990s they were involved in a multiprofessional regional group that worked to redact a law about out of hospital birth in Emilia-Romagna. The group stimulated the enactment of the regional law 26/1998, the first in Italy, that defined as maternity homes as places of birth, equal to hospitals and homes. The story underpinning the development of the project is summarized in Supplementary Digital Material 1, Supplementary Text File 2.

The standalone villa of the Il Nido is situated in the Navile borough of Bologna, inside a park that ensures a considerable green area all around the maternity home. Besides the park, other social areas including a kindergarten surround the building and give to users the possibility to stay in a relaxed and restorative atmosphere, in a peaceful outdoor space in connection with nature. These are elements that are known to promote relaxation and, in turn, to support physiologic birth ${ }^{38}$ (Figure 4).

The villa is separated by the rest of the street by a small driveway. It is easily reachable and

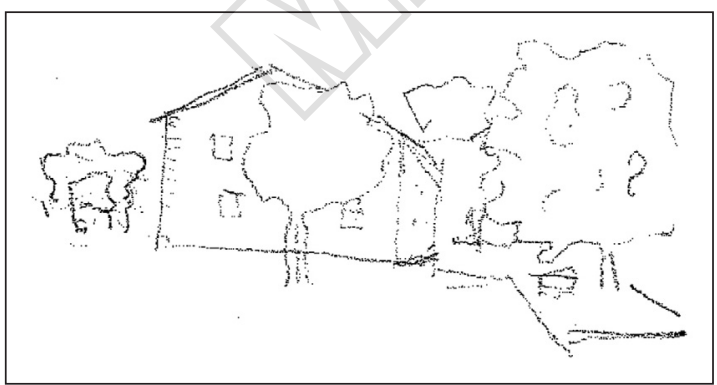

Figure 4.-External view of Il Nido Maternity Home. accessible thanks to a large parking area. It is located a few minutes walking or driving distance from one of the two main maternity hospitals of Bologna (Maggiore Hospital). The case data showed that this location was chosen purposefully, as it is close to the hospital in case of need, but far enough away to ensure independence from hospital models and facilities, so that the maternity home philosophy could be protected.

The maternity home comprises a two-floor house with a rectangular plan. The ground floor is dedicated mostly to social activities, while the first floor, where births take place, is designed as a more intimate space. This layout aimed to create a sense of spatial and emotional progression from the external and more public areas, to the inner and more private ambience, reflecting the different level of needs of the users.

The ground floor of the villa hosts the office of the association, a small common space where families can leave buggies and bags, a gym with changing rooms and toilets where meetings and birth classes occur, a small library, and a room that is generally used to host clinical activities of other professionals collaborating with the association. This floor continues through stairs with the first floor. The configuration and organization of the rooms and corridors delineate two areas; one whose rooms are mostly dedicated to counselling and consultation activities run by midwives; the other the most private birthing area of the house. The "consultation area" is also used to receive various treatment related to birth (i.e. shiatsu massages, naturopathy, acupuncture, osteopathy).

The birthing area, separated by a door from the nearby spaces, has a small kitchen, two rooms with en-suite toilets for families and a room with en-suite bathroom where midwives can rest or use when other rooms are busy. The separation of this space was seen as a fundamental element to guarantee privacy, but also, and especially to establish and nourish an optimal relationship between midwives and women. This is known to be crucial for optimal labor progress ${ }^{39}$ and it was an essential part of the social model of care espoused by the center (Figure 5).

In speaking about the maternity home, the midwives defined it as “our home, and women's 


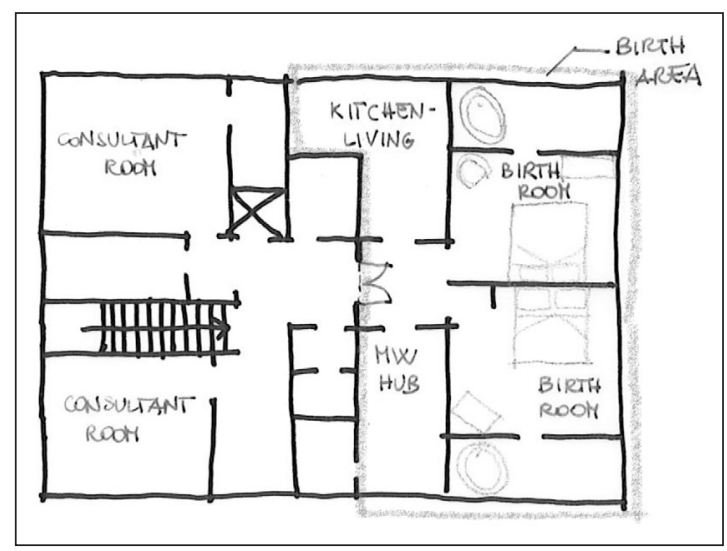

Figure 5.-Plan of second floor of Il Nido Maternity Home.

home." Indeed, this is how this space is literally perceived and approached. They reported taking care of the space in all its aspects, from the more clinical work, to the washing machine. The spaces were used to celebrate together their own as well as others' birthdays and/anniversaries. The behaviors reflect the concept that a maternity home does not just represent a home-like environment, but that it is more fundamentally created to be lived as a home for both the carers and the cared-ones.

Cross-case findings: childbirth space as an embodiment of birth philosophy

Table I summarizes the key features characterizing the design project and the actual environment of the two birth settings selected, in comparison to standard HLW. It outlines similarities and differences that can relate to the incorporation of salutogenic principles in birthplaces.

The following are the themes that appeared to be key from the analysis.

Designing new places for new models of care: a collective action

In both birth center cases the project underpinning the birth settings developed from collaborative work between health care professionals (i.e. doctors, midwives) architects and other stakeholders (i.e. association of users, governors, policy-makers). This seems to suggest that acknowledgment of health in maternity care as a concept beyond the mere absence of pathologies, is associated with awareness of the importance of organizing models and related spaces with consideration of the multiple perspectives that could impact on health. In particular, this resulted in great(er) care for listening to women and families' needs, in order to inform, confirm or modify the project plan.

\section{Translating concepts into spaces}

The spaces of both the birth center and the maternity home were planned to reflect a specific philosophy of care, according to which birth represents both a physiological event in a woman's life and one with social relevance. Underpinning both the projects there was the awareness of the need for changing spaces to fostering change in practice, especially in contrast to the over medicalization and overuse of interventions in current intrapartum care. Shared philosophical elements included the need for maximizing safe physiological birth, placing women and families at the center of the process, ensuring a kind and respectful care, and offering help not only with the physical aspects of childbirth but also supporting the parents towards parenthood. Professionals were considered to be partners of women and families in a relationship-based care approach. Spatial translations of such concepts include the idea of using convex spaces or a core cloister or the integration rather than separation of those areas for mainly staff-use (e.g. in Margherita), suggesting also a sense of belonging of professionals to the same community of users. Ensuring a connection with external landscape and contexts, either through direct access to natural green area (e.g. the park surrounding the Il Nido) or allowing a view to through windows, appeared to be physical means of connection with the broader social-context in which each birth occurs, as well as being directly associated with wellbeing. For the maternity home this philosophy was enacted through the choice of a house isolated in a green space that could promote relaxation and regeneration. For the birth center, the location choice consisted in the constitution of a new building outside the hospital, in a separate block, connected to the hospital, but still independent. Elements that usually seem to have no significant function for health care, such as corridors or outdoor spac- 
es, represented, in both the birth settings, spaces to be lived in and used as additional support for healthy processes related to childbirth.

\section{Ensuring safety}

Both the Margherita and the Il Nido appear to express through their environment a concept of safety that incorporates both similar physical safety elements as for hospital settings, and also more subtle attention to different concepts of safety that matter to women and families.

The location of birth settings shows a different connection with the host obstetric-led units and access to medical interventions in case of development of risk factors or emergencies. While in the Margherita project it was deliberately and carefully choose to create a connection of few meters distance alongside the hospital, the stakeholders of the Nido maternity homes did not consider to be a necessary characteristic to guarantee the same short-distance to the hospital, although they recognized the positioning of the structure few kilometers far from Maggiore Hospital to be a positive element. First-aid emergency protocols, equipment and drugs on-site to deal with any immediate problems, as well as quick access to medical-high-tech care and facilities in case of escalation of risks and obstetric emergency represented elements for safety across-cases.

However, in both the cases, the problem of safety was not restricted to these elements. The environment, indeed, seem to express the willingness of working on safety at a further level, enhancing the experience of women and partners of 'feeling safe', being in a place where people can feel the whole birth event protected, safe in a sort of maternal sense. The underpinning paradigm of safety appeared to move from a perspective that is centered on problems and pathologies and abundant ("just in case") use of interventions to deal with risks (that in most women and babies are only theoretical), to another approach that is focused on supporting and respecting physiological processes as means also to prevent complications and increase safety. This concept was visible through environmental choices such as hiding emergency medical equipment within furniture, or limiting it to the minimal appropriate within a home or home-like environment, to avoid the im- pression of a risk-centered culture. Moreover, the sense of safety as protection rather than treatment was translated by situating the birth scenario far from the flows of other activities and interferences (such as clinics, classes or meetings).

Spaces that are health/human-centered vs. pathology/machine/intervention-centered

The design of the two cases outlines the intent of giving space to human interactions more than to highly technical care. This can be visible through the choice of prioritizing space for intimacy, privacy, and human movements/relationships instead of prioritizing space for monitors and machines as it is standard in hospital labor ward settings. This is apparent also by looking at how common features of a birthing room are configured within the two case-sites. For instance, the birthing room has a bed that are - or look like - normal home-bed, placed in marginal-areas, instead of dominating the scene. Importance is given to free space for movement of women and birth attendants. This location of the bed highlights privacy and intimacy as a necessary component of the birth setting. Privacy and intimacy were guaranteed in both settings by creating 'mediated' access to the birth scene, through doors used to delineate an impression of a 'filtered' area, or by placing the birthing room in a space with no direct/automatic access from main entrance of the buildings.

\section{Discussion}

In the context of childbirth, the two cases investigated in this study exemplify the many forms of action that can be taken to shape an environment to promote health. ${ }^{6}$ Indeed, according to our results, the aim of enhancing health through the physical features of a birth setting could be achieved either by designing and creating a new birthspace within a hospital, or by reshaping an existing one, or by encouraging a move towards an out-of hospital ambience. In all forms, the environment can have salutogenic effects as long as its characteristics are informed by salutogenic principles.

According to $\mathrm{WHO},{ }^{40}$ key principles to be used in a multidisciplinary "whole system" ap- 
proach in order to promote health in a setting, include community participation, partnership, empowerment and equity. Community participation and partnership principles were apparent from the accounts of the design project, through the realization and the use of space in both the Margherita and the Il Nido birth settings. At the Margherita, the creation of core "cloisters" represent an efficient translation of the bio-psycho-social model of care of a birth centre, ${ }^{36}$ encouraging encounters, relationships and participation of users and staff in the general daily life of the unit. ${ }^{41,42}$ Furthermore, by grouping the birth rooms around a central area, the case of the Il Nido illustrated how the communication between humans and between spaces can be obtained more effectively than in linear-shaped settings. Findings hence outline that the translation of a social model of care in childbirth might go beyond the mere creation of a 'social space' in the setting, and be maximized by using the layout in a way that can be really functional to the pshyco-biological-social dynamics related to birth.

The convex/rounded curves characterizing the Margherita represent a mode of embodiment of the empowerment principle of healthy settings. As discussed by Lepori, the use of a spiral path while (re)shaping a setting can facilitate the perception of birth as an event that progressively evolves within a continuum. This ensures that the woman is placed at the center, enhancing her control of the process, 43 in contrast with the usual arrow-like pathway of traditional hospital labor wards that reflect an assembly-line approach to childbirth. ${ }^{44}$ Soft curves spontaneously facilitate encounters and sharing between colleagues. The space for debate and discussion could potentially enable midwives to be more confident in autonomous decision-making related to intrapartum care. ${ }^{45}$ Having spacious birthing rooms means that the bed does not need to be a standard hospital design, and it can be placed off-center, or even hidden until/unless it is needed, so that it does not dominate the birthing room, encouraging mobility for childbearing women. This kind of space safeguards privacy and intimacy, and provides support for women to create their own 'nesting area'46. Together with a focus on the importance of a positive midwife-woman relationship, these elements foster the physiological processes of labour 47,48 through a sense of being "safe enough to let it go" 49 , increasing the opportunity for most women to experience a normal birth. ${ }^{50}$ In this sense, the environment can empower also the "matrescence" process ${ }^{51}$ and enhance the likelihood that women will report positive birth experiences.52 The calming and relaxing effect of the homely environment of the birthing rooms ${ }^{51}$ was potentiated in both the case-settings by the calming and restorative spaces $^{53-55}$ offered by the visible green areas. Solutions such as the possibility of a direct connection with nature (e.g. having the opportunity of walking in the garden in labor) that were offered in the Il Nido provide a means of optimizing the benefits of the environment and, consequently of the birth process. $36,56,57$ Internally, as noted by Newburn and Singh, 58 a clean room with ensuite, comfortable furniture for women and their birth companions also positively influence birth experience and outcomes.

Finally, the empowering effect of a birth setting also seems to impact also on midwives and their care. Midwives have perceived their behaviors to be different in environments with different atmospheres. ${ }^{45,59,60}$ A homely environment has also been reported to increase the time spent by midwives with women, and this may partially explain the effects on women discussed above.

\section{Conclusions}

This article explores how virtuous examples of existing birth centers in Italy incorporate principles of healthy settings in their environment. The two examples of the Maternity Home Il Nido in Bologna and the Margherita Birth Centre in Florence have been analyzed. The description of their settings and the rationale behind their constitution (both spatial and organizational) and the way in which these factors seem to promote both health and wellbeing. The challenge lies in understanding which elements of a birth center (or any healthy birth setting) are responsible for the improved outcomes, and how these could be translated to other settings, such as hospital based labor wards, in future. The conclusions from both cases studies are important for deep- 
ening knowledge in this area, and for underlining the importance of thinking about the architectural and organizational aspects of birth spaces at every stage of planning, design, and delivery. Future research should also investigate how this knowledge can be translated in birth settings of both high- and low-income countries.

\section{References}

1. Whitehead D. The European Health Promoting Hospitals (HPH) project: how far on? Health Promot Int 2004;19:25967.

2. Gehl J. Life Between Buildings: Using Public Space. Washington: Island Press; 2011. p.43

3. WHO. The Ottawa Charter for Health Promotion. Geneva: World Health Organization; 1986; [Internet]. Available from: http://www.who.int/healthpromotion/conferences/previous/ ottawa/en/index.html [cited 2018, Oct 10].

4. Salingaros NA. Biophilia and Healing Environments: Healthy Principles For Designing the Built World. New York: Terrapin Bright Green LLC; 2015

5. Peters T. Super-Architecture: Building Better Health. Architectural Design 2017;87:24-31.

6. Golembiewski JA. Salutogenic Architecture in Healthcare Settings. In: Mittelmark MB, Sagy S, Eriksson M, Bauer G, Pelikan JM, Lindström B, et al., editors. The Handbook of Salutogenesis. Springer; 2017. p. 267-276

7. Nickl-Weller C, Nickl H. Healing Architecture. Schweiz: Braun Publishing AG; 2013.

8. WHO. Health Promotion Glossary. World Health Organization; 1998 [Internet]. Available from: http://www.who.int/ healthy_settings/about/en/ [cited 2018, Oct 10].

9. Dooris M, Poland B, Kolbe L, de Leeuw E, McCall D, Wharf-Higgins J. Healthy settings: building evidence for the effectiveness of whole system health promotion - challenges and future directions. In: McQueen DV, Jones CM, editors. Global perspectives on health promotion effectiveness. New York: Springer; 2007. p. 327-352

10. Lyon C. Humanist Principles, Sustainable Design and Salutogenics: A New Form of Healthcare Architecture. Architectural Design 2017;87:56-65.

11. Mazuch R. Salutogenic and Biophilic Design as Therapeutic Approaches to Sustainable Architecture. Architectural Design 2017;87:42-7.

12. Newburn M, Singh D. Creating a Better Birth Environment. Women's views about the design and facilities in maternity units: a national survey. National Childbirth Trust, London; 2003 [Internet]. Available from: https://www.nct.org.uk/ sites/default/files/related_documents/BBE_report_311003. pdf [cited 2018, Oct 10].

13. Hodnett ED, Downe S, Walsh D. Alternative versus conventional institutional settings for birth. Cochrane Database Syst Rev 2012;(8):CD000012.

14. Lepori B. Freedom of Movement in Birth Places. Children's Environments 1994;11:1-12.

15. Symon AG, Dugard P, Butchart M, Carr V, Paul J. Care and environment in midwife-led and obstetric-led units: a comparison of mothers' and birth partners' perceptions. Midwifery 2011;27:880-6.

16. Lawrence A, Lewis L, Hofmeyr GJ, Styles C. Maternal positions and mobility during first stage labour. Cochrane Database Syst Rev 2013;(8):CD003934.

17. AusHFG. Part B. Health Facility Briefing and Planning HPU 510 Maternity Unit; 2017 [Internet]. Available from: https://www.healthfacilityguidelines.com.au/health-planningunits [cited 2018, Oct 10].

18. Department of Health. Health Building Note 09-02: Maternity care facilities; 2013 [Internet]. Available from: https:// www.gov.uk/government/publications/ [cited 2018, Oct 10].

19. FGI. Guidelines for Design and Construction of Hospitals; 2018 [Internet]. Available from: http://www.madcad. com/store/subscription/FGI-Guidelines-Hospital-2018/ [cited 2018, Oct 10].

20. Ispsel Guidelines. Linee guida per gli interventi di prevenzione relativi alla sicurezza e all'igiene del lavoro nel blocco parto. Istituto superiore per la prevenzione e la sicurezza del lavoro; 2007 [Internet]. Available from: https:// appsricercascientifica.inail.it/ [cited 2018, Oct 10].

21. Schreuder E, van Heel L, Goedhart R, Dusseldorp E, Schraagen JM, Burdorf A. Effects of Newly Designed Hospital Buildings on Staff Perceptions: A Pre-Post Study to Validate Design Decisions. HERD 2015;8:77-97.

22. Ariadne Lab. MASS. Designing Capacity for High Value Healthcare: The Impact of Design on Clinical Care in Childbirth; 2017 [Internet]. Available from: https://www.ariadnelabs.org/ [cited 2018, Oct 10].

23. Felli $\mathrm{P}$, Lauria A. La Casa di Maternità: una struttura sociale per il parto fisiologico. Linee guida per la progettazione. Pisa: Edizioni ETS; 2006.

24. Lab.our Ward. Showcasing Birth in Progress: A walk-in maternity ward and co-design exhibition June 10; 2016 [Internet]. Available from: http://labourward.org/showcasing-birthin-progress/ [cited 2018, Oct 10].

25. Dahlen HG, Downe S, Wright ML, Kennedy HP, Taylor JY. Childbirth and consequent atopic disease: emerging evidence on epigenetic effects based on the hygiene and EPIIC hypotheses. BMC Pregnancy Childbirth 2016;16:4.

26. Kitzinger S. Rediscovering the social model of childbirth. Birth 2012;39:301-4.

27. Leboyer F. A birth without violence. Milan: Garzanti; 1973.

28. Odent M. Nascita dell'uomo ecologico. Milan: RED edizioni; 1981.

29. Rowe RE, Townend J, Brocklehurst P, Knight M, Macfarlane A, McCourt C, et al. Service configuration, unit characteristics and variation in intervention rates in a national sample of obstetric units in England: an exploratory analysis. BMJ Open 2014;4:e05551.

30. Odent M. Nascita dell'uomo ecologico. Milan: RED edizioni; 1981. p.67.

31. Educaweb. La prima stanza del parto naturale in Italia: intervista a Barbara Grandi; 2016 [Internet]. Available from: https://www.educaweb.it/notizia/2016/11/14/prima-stanzaparto-naturale-italia-intervista-barbara-grandi-10651/ [cited 2018, Oct 10].

32. "Ministero della Salute-Comitato Percorso Nascita nazionale. Linee di indirizzo per la definizione e l'organizzazione dell'assistenza in autonomia da parte delle ostetriche alle gravidanze a basso rischio ostetrico (BRO)"; 2017.

33. Nascere in casa. Associazione Nazionale Culturale Ostetriche Parto a Domicilio e Casa Maternità; [Internet]. Available from: http://www.nascereacasa.it/ [cited 2018, Oct 10].

34. Nascere in casa. Tutte le case maternità in Italia [Internet]. Associazione Nazionale Culturale Ostetriche Parto a Domicilio e Casa Maternità; [Internet]. Available from: http:// 
www.nascereacasa.it/tutte-le-case-maternita-italia/ 2018, Oct 10].

[cited

35. Rowe R. Birthplace terms and definitions: consensus process. Birthplace in England research programme. Final report part 2. NIHR Serv Deliv Organ Program; 2011 [Internet]. Available from: http:/www.netscc.ac.uk/hsdr/files/project/ SDO_FR2_08-1604-140_V02.pdf [cited 2018, Oct 10].

36. Rocca-Ilhenacho L, Batinelli L, Thaels E, Rayment J, McCourt C. Midwifery Unit Standards; 2018.

37. Watson Lubic R. The birth Centre Concept; 1992.

38. Foureur MJ, Leap $\mathrm{N}$, Davis DL, Forbes IF, Homer CE. Developing the Birth Unit Design Spatial Evaluation Tool (BUDSET) in Australia: a qualitative study. HERD 2010;3:43-57.

39. Dahlberg U, Aune I. The woman's birth experience---the effect of interpersonal relationships and continuity of care. Midwifery 2013;29:407-15.

40. WHO. Healthy Settings [Internet]. Available from: http:// www.who.int/healthy_settings/about/en/ [cited 2018, Oct 10].

41. Berridge EJ, Mackintosh NJ, Freeth DS. Supporting patient safety: examining communication within delivery suite teams through contrasting approaches to research observation. Midwifery 2010;26:512-9.

42. Foureur M, Davis D, Fenwick J, Leap N, Iedema R, Forbes I, et al. The relationship between birth unit design and safe, satisfying birth: developing a hypothetical model. Midwifery 2010;26:520-5.

43. Lepori B, Foureur M, Hastie C. Mindbodyspirit architecture: Creating birth space. Birth Territ midwifery Guard Theory Pract. Educ Res 2008;1:95-112.

44. Walsh D. Subverting the assembly-line: childbirth in a free-standing birth centre. Soc Sci Med 2006;62:1330-40.

45. Iannuzzi L. An exploration of midwives' approaches to slow progress of labour in birth centres, using case study methodology 2016 [Internet]. Available from: http://eprints. nottingham.ac.uk/id/eprint/37758 [cited 2018, Oct 10].

46. Baby Centre. Creating the perfect environment for giving birth; [Internet]. Available from: https://www.babycentre. co.uk/a1028257/creating-the-perfect-environment-for-giving-birth [cited 2018, Oct 10].

47. Romano AM, Lothian JA. Promoting, protecting, and supporting normal birth: a look at the evidence. J Obstet Gynecol Neonatal Nurs 2008;37:94-104, quiz 104-5.
48. Lothian JA. Do not disturb: the importance of privacy in labor. J Perinat Educ 2004;13:4-6.

49. Anderson T. Feeling safe enough to let go: the relationship between a woman and her midwife during the second stage of labour. Houndmills, UK: Palgrave Macmillan; 2000.

50. Prosser SJ, Barnett AG, Miller YD. Factors promoting or inhibiting normal birth. BMC Pregnancy Childbirth 2018;18:241.

51. Walsh DJ. 'Nesting' and 'Matrescence' as distinctive features of a free-standing birth centre in the UK. Midwifery 2006;22:228-39.

52. Homer CS. Home-like environments for labour and birth: benefits for women and babies. Evid Based Med 2013;18:e32. 53. Mitchell DR. Design Characteristics of Restorative Spaces: A Manual for College Campuses; 2015 [Internet]. Available from: http://s3.amazonaws.com/chssweb/ documents/19291/original/Mitchell Graduate Project

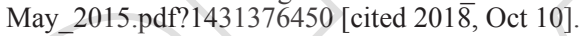

54. Kaplan R, Kaplan S, Ryan R. With people in mind: Design and management of everyday nature. Washington D.C. Island Press; 1998

55. Hartig $\mathrm{T}$. Restorative environments. In: Spielberger $\mathrm{C}$, editor. Encyclopedia of applied psychology. San Diego, CA: Academic; 2004. p. 273-9.

56. Singh D, Newburn M. Feathering the nest: what women want from the birth environment. RCM Midwives 2006;9:266-9.

57. Forbes I, Foureur M, Leap N, Homer C. Birthing Unit Design: Researching New Principles. World Health Design Magazine; 2008 [Internet]. Available from: http://www. worldhealthdesign.com/birthing-unit-design-researchingnew-principles.aspx [cited 2018, Oct 10].

58. Newburn M, Singh D. Are Women Getting the Birth Environment They Need? A Report of a National Survey of Women's Experiences. London: National Childbirth Trust; 2005

59. Hodnett ED, Stremler R, Weston JA, McKeever P. Reconceptualizing the hospital labor room: the PLACE (pregnant and laboring in an ambient clinical environment) pilot trial. Birth 2009;36:159-66.

60. Bourgeault IL, Sutherns R, Macdonald M, Luce J. Problematising public and private work spaces: midwives' work in hospitals and in homes. Midwifery 2012;28:582-90.

Conflicts of interest.- The authors certify that there is no conflict of interest with any financial organization regarding the material discussed in the manuscript.

Funding.-This paper contributes to the EU COST Action IS1405: BIRTH: "Building Intrapartum Research Through Health - an interdisciplinary whole system approach to understanding and contextualising physiological labour and birth" (http://www.cost.eu/ COST_Actions/isch/IS1405), supported by COST (European Cooperation in Science and Technology).

Authors' contributions. - Soo Downe, Nicoletta Setola and Laura Iannuzzi developed the project; Grazia G. Cocina, Eletta Naldi, Nicoletta Setola, Sandra Morano, Lucia Branchini, Laura Iannuzzi focused on the background information; Marco Santini and Lucia Branchini mainly contributed to collecting the narrative accounts on the birth settings design projects. All coauthors contributed to the writing-up of the paper that was assembled by Nicoletta Setola and Laura Iannuzzi under the supervision of Soo Downe .

Acknowledgements. - The authors would like to thank all the staff working at the Margherita Birth Centre and the Il Nido Maternity home. A special thanks to Vianella Gnan for the support in collecting information from the Il Nido, and the association Mondodonna for facilitating data collection.

Article first published online: October 5, 2018. - Manuscript accepted: October 1, 2018. - Manuscript received: September 26, 2018. For supplementary materials, please see the HTML version of this article at www.minervamedica.it 